\title{
Strategies for Gaining and Maintaining Employee Trust in Private and Public Institutions. The Case of University of Derby (UK) and Valley View University (Ghana)
}

\author{
Yvette Ferguson Arthur \\ Derby School of Business, University of Derby, United Kingdom \\ Andrew Osei-Agyemang \\ School of Finance and Economics, Jiangsu University, Zhenjiang, China \\ John Kingsley Arthur \\ Computer Science Department, Valley View University, Ghana
}

\begin{abstract}
Trust in the relation of the employer to employee is a key determinant to the success of every organization. Several research has been done on this subject matter but little attention is paid to educational instituitions. Therefore, the objective of this research is to identify and examine the strategies for gaining and employee trust in with emphasis on large organizations, and also to determine the impact of employee trust in both private and public educational institutions. Both quantitative and qualitative techniques are deployed to perform analysis on data collected from respondents from University of Derby, United Kingdom; and Valley View University, Ghana. Factors common to both case studies for gaining employee trust are the use of consistent approach, managers been role models, equal treatment of employees, similar work load, and team praise. Some recommendations are made to further improve the work.
\end{abstract}

Keywords: Employee trust, Organizational performance, employee outcomes

DOI: $10.7176 / \mathrm{EJBM} / 11-33-09$

Publication date: November $30^{\text {th }} 2019$

\section{Introduction}

Trust plays a significant role in corporate culture (Perry \& Lawrence, 2004), and it is a critical determinant of the success of an institution. Organizations are thought of as a network of transactions and also a cluster of a social network. Ignoring the people's dimension, treating people as mere cogs in the machine, results in the full contribution they can make lost (STUC, 2009). McCauley and Kunert (1992) conclude that trust between individuals and groups within organizations is a highly valuable ingredient in the long term stability of the organization and the well-being of its members.

Also, as reported by Deloitte (2010), nearly half (48\%) of employed Americans who plan to look for a new job when the economy is more stable, cited a loss of trust in their employer as a result of a reason for the intention to leave. Given this background, employee trust must be of great concern to managers, shareholders, and owners of an organization, including the educational sectors. Managers can tackle this by increasing the levels of trust to effectively deal with the impacts and effects of lack of trust, Gill (2008). Gill (2008) related employee dissatisfaction and poor dedication issues to a lack of trust in organizations. Besides, their research explained that an employee's level of dissatisfaction and dedication has a massive impact on the profitability of an organization. Several research works have done in the area of trust and organizations but little attention is given to the academic institutions. Therefore, this research work seeks to identify and examine the strategies for gaining and maintaining employee Trust in large organizations, and also to study the impact of employee trust in high educational institutions considering both the private and public universities.

\section{Literature Review}

\subsection{The Role and Importance of Trust in Organizations}

The term trust has been an area of interest due to its significant impact on the business environment. It is another crucial element that profoundly influences the future success of the organization as well as an issue that permeates across all aspects of the organization. In addition, Lear(2003) argued that building upon trust in business would increase an employee's commitment. A higher level of commitment means a higher level of customer service. Hence trust does not only produce a high output but high customer service and customer satisfaction.

Summary: Employees' commitment is relative and increases with trust, which is showcased in higher customer service satisfaction.

Moorman et al. (1992) present that commitment is related to the value of something. In their findings, they identified a few roles of trust in organizations. First, trust in an organization is seen as a determinant of relationship 
management in business. This is because trust triggers the quality of interactions.

Summary: Trust is directly proportional to quality interaction, such that as employee and employer interaction is empowered, trust increases.

In the work of Boe(2002), it is found that trust has a significant role in the output of an employee. An employee thinks about the future of the business and its success, due to the fact that they are allowed to take their initiative as well as ownership of jobs. Trust plays a role in creativity, as seen in Motorola and Anderson Windows, where the level of trust is high. These companies have understood the philosophy of trust, where their employees are willing to give each other a shoulder to lean on, and management is ever open to suggestions. Since employers are open to suggestions, it gives room for employees to suggest their ideas.

Summary: Trust might enhance creativity with the presence "sense of ownership" feeling of an employee.

Trust plays a significant role in the social exchange theory for long term orientation(Jiang et al., 2011). The social exchange theory is used to explain the relational exchanges between two organizations. The theory explains that trust is developed through a consistent exchange of benefits between two employees. Nevertheless, these benefits are hardly specified or negotiated but depend on the party's voluntary fulfillment of the agreement. There is a mediating role of the supervisor's trustworthiness in the organization. Also, an increase in employee's trust in his leaders results in an increase in job satisfaction.

Summary: Job satisfaction might be increased as employees' trust in management/leaders increases.

Gould-Williams(2010), on the other hand, submits that trust in the workplace plays a role in organizational performance, and this is done by adapting Human Resource (HR) practices. He further explained that trust is essential in improving performance. From his theoretical model on performance, he identified that there is an impact of HR practices on trust, which in turn affects the organization. This is because HR practices predict changes in employee performance and satisfaction and organizational commitment and performance.

Summary: Trust for employees might enhance organizational performance, and it has a bearing on HR practices.

\subsection{The Impact of Employee Trust on the Organization}

The impact of employee trust on an organization is relevant to gaining and maintaining it (Boe, 2002). However, this review will concentrate on why organizations should be interested in maintaining and gaining trust and what happens if they ignore it.

2.2.1 High Level of Trust or Availability of Trust

Sharkie(2009) suggest that employee output run above expectation and will also depict extra-role behaviors when there's a positive employee trust in the organization. This is simply because employee trust serves as a facilitator for a good communication channel. Extra-role behavior is dependent on trust, where both components are influenced by employees' expected benefits and costs. If there is a sign of low employee trust or lack of employee trust, productivity will also be affected (Nikandrou et al., 200; Boe, 2002). This is because employees are working in an environment that lacks trust will feel reluctant to put in their very best in generating positive outcomes.

Summary: low trust might affect productivity negatively since higher trust will call for an employee working beyond expectation.

2.2.2 Low Level or Lack of Trust

Katinka and Koopman (2003) suggest that a lack of trust is influenced by past experiences and the chances to have interactions in the future, which are both relevant within every organization. Hence the impact of this on the organization will negatively affect the employee's willingness to cooperate and also affect positive expectations of the future. Some key critical indicators of lack of trust such high employee turn over, low customer turnout, and no corporation for employee recruitment management programs(Boe, 2002).

Summary: Higher rate of employee turnover is inversely proportional to trust, and it negatively affects the organization

\subsection{The Impact of Employee Trust on the Organization}

Employee trust has been identified as key in the growth and success of an organization. However, organizations must equip themselves with the knowledge of developing new and attractive strategies in order to gain and maintain the level of employee trust. Some strategies identified are a family gathering, family fairness, Management expectations, Establish boundaries, delegate appropriately, and consistency.

By family gathering, all members of the family are induced with a sense of closeness and bonding. Some organizations, likewise, do organize staff gatherings to foster the same psychology of belongingness. By that, employees have the chance to air out their oppressions and appraisals, which foster balanced growth of the employee and its stakeholders.

All members of an organization will like to be treated on the same level as their colleagues. Employees will trust their managers if they believe there is no visible form of partiality in the organization.

The confidence of a manager's consistency can be attributed to setting clear expectations from employees and 
acknowledging when it has been met(Zemke, 2000). It is more efficient for managers to praise teamwork than individual work on a daily basis. Positive feedback makes employees feel that their work is appreciated. Management should also make it clear to employees, especially the new ones, as to what "unwritten rules" rules to obey. This will give an employee no room to make accidental mistakes. However, some employees will prefer individual appraisal to know how efficient they are.

Trust can be built when employees are given roles and guidance on how to communicate with people within larger organizations (Zemke, 2000). Management should not tackle boundaries as a separate entity but should tackle them as one factor that can promote the establishment of relationships by serving as a point of exchange. An example is that employees of the marketing department can get answers from their colleagues on work-related questions. Quite apart from Zemke(2000), there will be some individuals in the workplace who will prefer to work under their initiatives, and therefore, the direction of Zemke(2000) will not hold in that perspective.

Improper method of delegating duties can be one factor that will influence the level of trust. However, orienting employees on what to do, who is to do what, and why the work has been delegated, as well as delegating authorities for the various duties, can give rise to trust. Also, giving employees the same quality of work on a rotational basis will leave little room for an employee to feel a sense of discrimination.

Consistency is important in the way an employer conducts his business and in his/her dealings with employees. A good manager can be seen to be consistent and at the same time, flexible (Fracaro, 2008).

Summary: Cooperation events such as organization outing would create a sense of belongingness and might help maintain trust. Well-defined job functionality would influence the maintenance of trust in an organization. Methodologies used in the delegation of work would influence the maintenance of trust since inferior methods would create a sense of discrimination.

\section{Methodology}

In this research work, both quantitative and qualitative approaches are used. The cross-sectional and case A dual strategy is adopted for the research, namely, the cross-sectional and case study. The cross-sectional study will be used to gather data from employees in different cultures and countries but in the same period. Two different countries (UK and Ghana) were used to ascertain how their opinions on the topic differ.

\subsection{Population and Sample}

The group of interest to the researcher was employees of the Business School at the University of Derby and the School of Business, Valley View University. The target population was supervisors of independent postgraduate students as well as undergraduate module leaders. The questionnaires were administered to all members of the sample. This selection is made on purposive or judgemental sampling for the comparative nature of the study.

\subsection{Data Collection and Data Analysis}

Both primary and secondary data are collected; that is from literature (the articles, and books, etc.) and admiration of online questionnaire form to respondents to fill. Questions like how the employee will define trust, whether trust is important, what factors affect trust in the organizations, will be asked. The questions will produce quantitative data that will be highly specific and precise. However, the qualitative data derived was converted into quantitative data for analysis. The researcher will use the Statistical Product for Service Solutions (SPSS) for the data analysis.

\subsection{Questionnaire Design}

The questionnaire is divided into two(2) sections. The section captures the background information such as age, gender about the respondents. The section will also contain questions like years of experience, level of qualification and place of work. The section 2 asks questions about the strategies for gaining and maintaining employee trust. This section had the respondents answer questions on what strategies would affect their trust for their managers. Respondents will be given a set of options of which they will have to rate on a scale of 1-5, that is, 1 representing essential and 5 representing not essential.

\section{Analysis and Discussion of Results}

The questionnaire is divided into two(2) sections. The section captures the background information such as age, gender about the respondents. The section will also contain questions like years of experience, level of qualification, and place of work. Section 2 asks questions about the strategies for gaining and maintaining employee trust. This section had the respondents answer questions on what strategies would affect their trust for their managers. Respondents will be given a set of options of which they will have to rate on a scale of $1-5$, that is, 1 representing essential and 5 representing not essential. 
4.1 Analysis of the Strategies for Gaining and Maintaining Employee Trust in Large Organization

In order to identify the effective strategies for gaining and maintaining employee trust in larger organizations, employees were asked to rank the factors that are most important in affecting TRUST between themselves and their managers. The factors include social outing, team praise, equal treatment, similar workloads, and consistent approach and considering employee circumstances and managers as a role model.

Below is the bar chart for social outing showing the number of respondents, percentage valid, and the cumulative percent. It can be realized that most of the respondents accepted that social outing on the part of managers could not be an essential factor affecting trust in the organization. The study showed that $53.3 \%$ agreed that it was least important as compared to the $16.7 \%$ who said it was necessary.

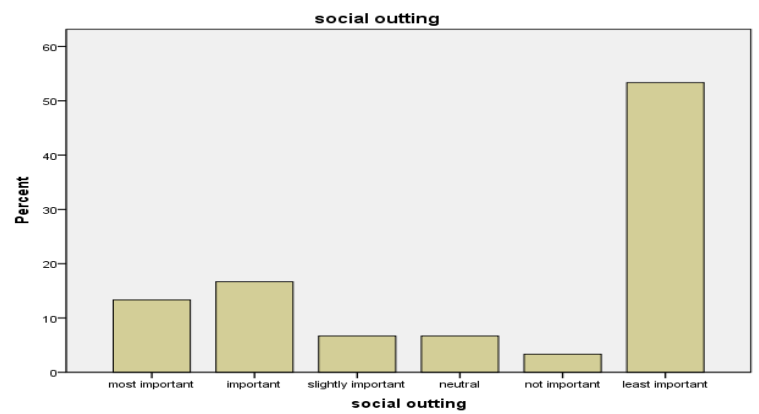

Figure 1: Chart representing Social outing as a factor affecting employee trust

From figure 1, sixteen(16) respondents did not agree to the fact that if managers organized a social outing, it would increase their trust. Hence the data turns to dispute the findings of Boe (2002), who identified that employee trust increases when management organizes staff outings for employees.

Concerning the treatment is given to employees by managers, respondents' belief that equal treatment with no visible form of partiality most importantly affects the trust of employees. This, however, sides with Boe (2002) that employees will trust their managers if they believe there is no visible form on partiality in the organization. From the findings, $46.7 \%$ of the respondents agreed that equal treatment by managers would affect trust as compared to the $3.3 \%$ who said it is least important.

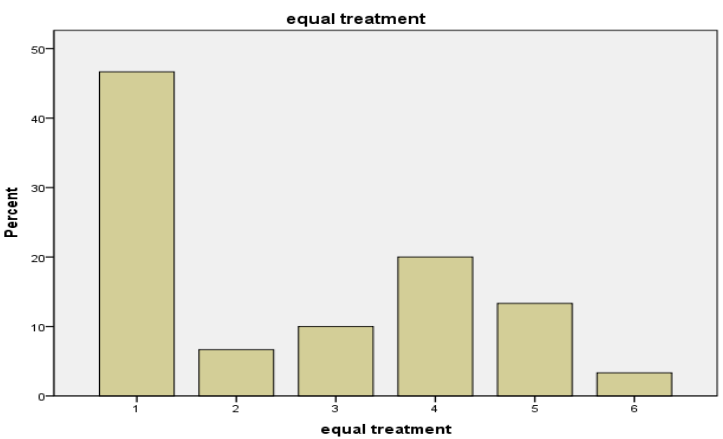

Figure 2: Chart showing the ranking of equal treatment as a factor that influences employee trust

Out of the thirty(30) respondents asked whether equal treatment on the part of managers could affect the trust level of employees, fourteen of them said it is most important as shown in figure 2.

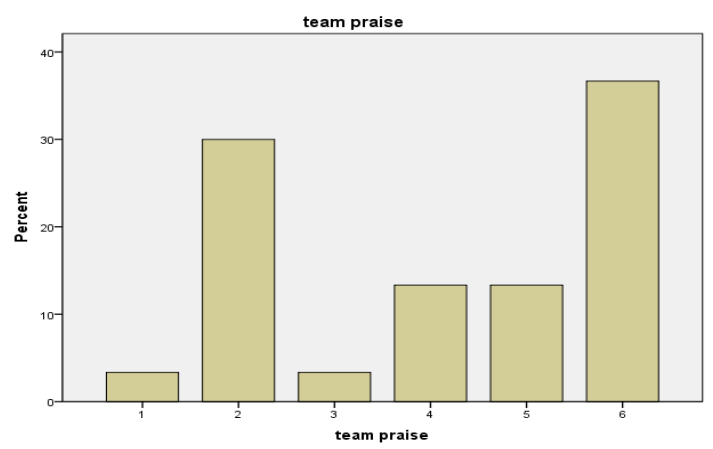

Figure 3: Chart showing the ranking of team praise as a factor that influences employee trust

$36.7 \%$ of the respondents out of the $100 \%$, team praise is least important when it comes to the trust in an 
organization. They form the majority opinion. Although $30.0 \%$ of the respondents said team praise is important when managers should resort to it. This factor, however, contradicts with Hunchak (2006) findings where he gathered that team praise increases employee trust. Also almost $26.6 \%$ agree that it is not important to employ team praise at all when it comes to trust. This means that simple majority of the respondents totalling $63.3 \%$ see it not as important to use team praise when it comes to trust. Generally, the findings have proven beyond all doubt that when managers praise the team it does not affect the trust individual team members have for the organization. As discussed above, figure 3 shows that nineteen respondents think that team praise does not foster trust as oppose by the eleven who think that it is important.

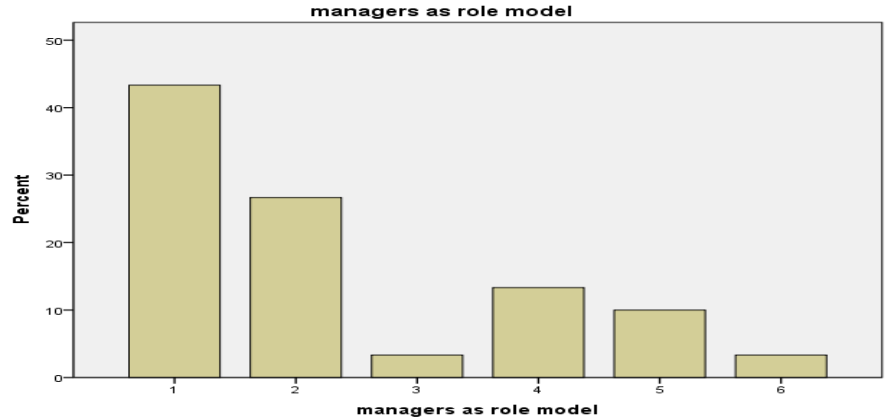

Figure 4: Chart showing the ranking of managers as role model as a factor that influences trust

The research has demonstrated that when the managers serve as role models to their employees, it boosts the trust levels. This means that every employee looks up to their managers in terms of the trust. $43.3 \%$ forming the majority agree to the fact that it is most important for managers to exhibit trust in order to influence their employees. More so, $26.7 \%$ of the respondents express the same idea to affirm the importance of role models by managers. In all, $70.0 \%$ of the respondents have agreed to this factor been the most important to employee trust in every organization. On the other hand, $13.3 \%$ think that it is least important when it comes to managers serving as a role model. Gillespie \& Mann(2004), Russell \& Stone(2002) and Nair(1994) shared similar views. According to Gillespie \& Mann(2004), the manager's leadership style and attitude influence employee trusts. He further discovered in his findings that managers being a role model to employees influences the employees' trust for his/her manger. From figure 4 above, it is realized that more than half (twenty-one) of the respondents support the factor under discussion.

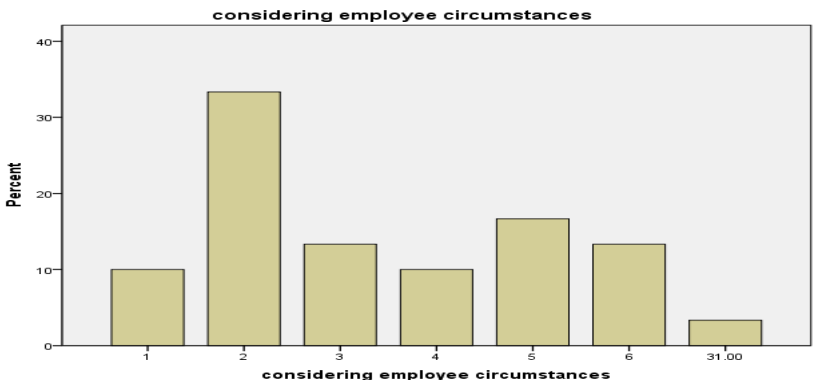

Figure 5: Chart showing the ranking of 'considering employee circumstances' as a factor that influences trust

The frequencies in figure 5 show that ten (10) of the respondents totaling $33.3 \%$ are of the view that considering the employee circumstances, it contributes to the level of trust, and three (3) of these respondents summing up $10.0 \%$. In all thirteen (13) respondents or $43.3 \%$ agree that to increase the trust of employees, managers need to consider their circumstances as illustrated in figure 5 above. 


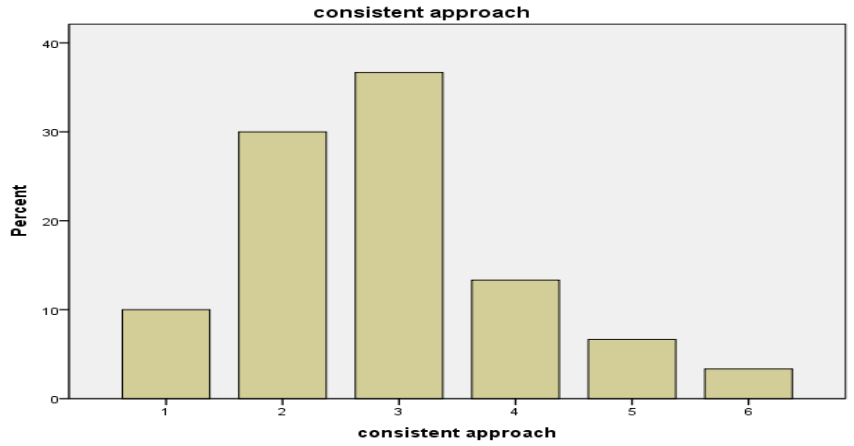

Figure 6: Chart showing the ranking of consistent approach as a factor that influences trust

Figure 6 illustrates that the majority of the respondents think it is slightly crucial for employees to exhibit trust if their managers should use a consistent approach. Respondents in both countries have shown that if managers would like to implement a consistent approach, it may be essential to affect the trust of the employees. Nevertheless, (Zemke, 2000), on the other hand, argued in his findings that a manager's consistency approach turn to influence an employee trust profoundly. However, these findings contradict that of (Zemke, 2000).

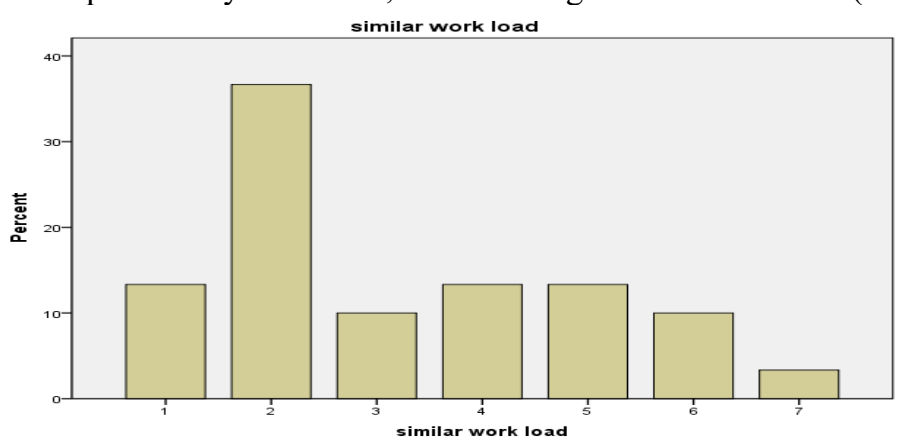

Figure7: Chart showing the ranking similar work load as a factor that influences trust

The figure 7 demonstrates that eleven (11) respondent's belief that it is important when managers give similar work load to employees since this would foster trust, this takes $36.7 \%$ of the overall percentage. On the other hand, four (4) or $13.3 \%$ out of the thirty (30) respondents also think that sharing of similar work load to employees by managers foster or increases trust among managers and employees. So we can conclude that, $50.0 \%$ of the respondents constituting half of the respondents attest to this factor as important when it comes to trust.

Based on the analysis provided to answer of the first objective, the findings identified the following factors in order of importance (with respect the percentage obtained for most important and important) to foster or promote trust among managers and employees. These factors are: Managers as a role model (70.0\%), Equal treatment $(53.3 \%)$, Consistent approach (50.0\%), Similar work load (50.0\%), and Considering employee circumstance $(43.3 \%)$. On the contrary out of the factors that could possibly affect employee trust the findings proved that the following factors do not affect the employee trust for their managers: Social outing $(56.6 \%)$, and Team praise $(50.0 \%)$

4.1 Analysis of Objective 2: Impact of Employee Trust In Higher Education, both public and private Institutions. Concerning the objective two - the impact of employee trust in higher education in both private and public institutions, we realize that the respondents from both universities (UoD and VVU) had no reservations when it comes to the fact that their output is likely to exceed expectation when they trust their managers. From the findings taking into consideration, respondents who checked agree and agree summed up to twenty (20), which is $66.7 \%$ of the total respondents. Since the number exceeds more than half of the total number of respondents, the conclusion to be drawn here is that trust is much dependent on the output of the employee. Although about $10.0 \%$ of the respondents thought; otherwise, it is largely agreed by employees of both the public and private universities that their output promotes trust, as shown in figure 8. This findings side with the research outcome of Boe (2002), which states that employees' trust is relatively linked to the work output.

To answer the question of low employee trust leads to the increasing rate of employee turnover, the findings showed that respondents who checked "agree" sum up to twenty (20), which is $66.7 \%$ of the total respondents. Since the number exceeds more than half of the total number of respondents, the conclusion to be drawn here is that trust is much dependent on the output of the employee, although about $16.6 \%$ of the respondents thought. 
Otherwise, it is a larger populace from both the public and private universities that have shown that their output promotes trust, as shown in figure 13. This finding contradicts the findings of Boe (2002), who explains that employees' trust influences the number of employee turnover in an organization. He added that where there exists a high level of employee trust, employee turnover is low and vice versa.

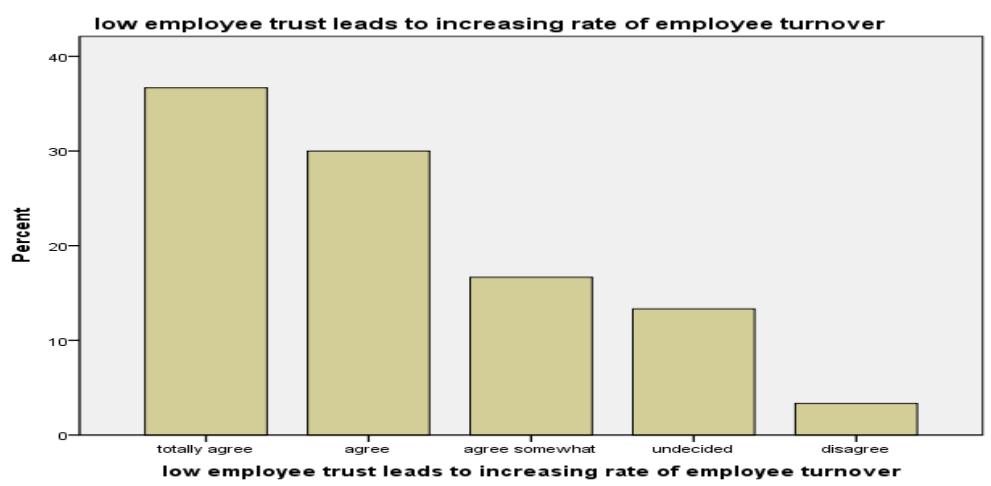

Figure 8: Low employee trust leads to increasing rate of employee turnover

\section{Conclusion and Recommendations}

Trust can be gained in different ways. Every manager and his management have a way or ways of gaining the trust of their employees. However, the case study produced some disputes and agreements in line with the literature reviewed. The case study also falls in the category of larger organizations, as explained by Digium(2019), as having more than 1000 employees. From the literature review, the following ways of gaining employee trust were identified; Managers as a role model, Equal treatment, Consistent approach, Similar workload, Considering employee circumstance, Social outings, Team praise.

However, based on the findings, the respondents did not agree to all the factors as being important. The following were accepted as essential factors/way through which trust can be gained, and this answers the research question; Managers as a role model, Equal treatment, Consistent approach, Similar workload, and Considering employee circumstance.

In the work of Boe (2002), he found out that the lack of trust in an organization will have a negative impact on the organization. He further explained that employee trust is associated with the employees' output, and since the employee is a key player in the organization, the lack of trust will negatively affect the organization. The findings of this research are in agreement with the work of Boe(2002). The respondents believe that employees' output is highly influenced by the level of trust. Hence when trust is lacking, and employees' work output will be poor. Low output has a negative impact on the overall productivity of the organization. In addition, when trust is lacking, it turns to reduce the number of customers the organization has (Boe, 2002). This is due to the fact that employees will no longer be willing to put the customer first, as this is the paradigm of every organization.

Therefore, managers of both the public and the private universities will need to pay attention to strategies examined and moderate it to achieve better performance with their employees, especially in the regional areas of the United Kingdom and Ghana respectively.

Further work can be done by increasing the number of case studies and performing a comparative study. It is likely to unveil exciting dimensions.

\section{References}

Perry, Ronald W.; Mankin, Lawrence D, 2004. Understanding Employee Trust inManagement: Conceptual Clarification and Correlates. Vol 33 pages 277-290.

STUC. 2009, Employee Trust and Motivation

Dan P. McCauley, Karl W. Kuhnert,(1992), A theoretical Review and Empirical investigation of Employee Trust in Management.

Deloitte. (2010). Trust in the workplace. 2010 ethics and workplace survey. Retrieved from

http://www.deloitte.com/assets/Dcom/UnitedStates/Local\%20Assets/Documents/us_2010_Ethics_and_Workpla ce_Surve_report_071910.pdf

Gill S. (2008). The role of trust in employee-manager relationship. International Journal of Contemporary Hospitality Management. 20 (1), 98 - 103.

Lear G. (2003). The importance of trust to organizational success .Available:http://www.rdsnet.com/articles/The\%20Importance\%20of\%20Trust\%202009.pdf

Tammy A. Boe (2002). Gaining and/or Maintaining Trust in Service Organization.

Jiang Z, Henneberg S and Naude P. (2011). The importance of trust vis-a-vis reliance in business relationships: some international findings. International marketing review. 28 (4), 318-339. 
Gould-Williams J. (2010). The importance of HR practices and workplace trust in achieving superior performance: A study of public-sector organizations. The International Journal of Human. 14 (1), 28-54.

Sharkie, R. and Reychav I. (2010). Trust: an antecedent to employee extra-role behaviour. Journal of intellectual capital. 11 (2), 227-247.

Nikandrou, et. al(2000) Gaining employee trust after acquisition; Implications for managerial action, Employee relations, vol 22 No. 4 pg 334-355

Katinka, B. andKoopman, P. (2003),"Introduction: trust within organisations", Personnel Review, Vol. 32 Iss: 5 pp. $543-555$

Zemke, R.(2000). Can You Manage Trust? Training, 37. 76-83

Gillespie A.N and Mann L. (2004). Transformational leadership and shared values: the building blocks of trust. Journal of Managerial Psychology. 19 (6), 588-607.

Russell R.F and Gregory S. (2002). A review of servant leadership attributes: developing a practical model. Leadership \& Organization Development Journal. 22 (3), 145-157

Digium Content Marketing Team.(2019). SMB, SME, and Large Enterprise: Why Your Business Size Classification Matters. Retrieved from http://www.digium.com/blog/2016/02/18/smb-sme-large-enterprisesize-business-matters/

Hunchak D. (2006). Misleading trust. Industrial Engineer: IE. 1 (10), 7-38. 